\title{
La lógica del tener, del deber y de la gratuidad en política pública: hacia un dispositivo de observación ${ }^{1}$
}

\author{
Patricio Miranda Rebeco et alii ${ }^{2}$ \\ FACULTAD DE CIENCIAS SOCIALES \\ PONTIFICIA UNIVERSIDAD CATÓLICA DE CHILE \\ pmirandr@uc.cl
}

\section{INTRODUCCIÓN}

Poco más de cuatro décadas después de Populorum Progressio Benedicto XVI se pregunta "hasta qué punto se han cumplido las expectativas de Pablo VI siguiendo el modelo de desarrollo que se ha adoptado en las últimas décadas" ma del desarrollo en la actualidad está estrechamente unido al progreso tecnológico [...]. La técnica-conviene subrayarlo- es un hecho profundamente humano, vinculado a la autonomía y libertad del hombre [...]. Por eso, la técnica nunca es solo técnica”“ . El problema es que, como ya había sido vislumbrado por Pablo VI, en la sociedad actual persiste la hegemonía de la visión tecnológica del desarrollo lo que "exige [...] una honda revisión con amplitud de miras del modelo de desarrollo, para

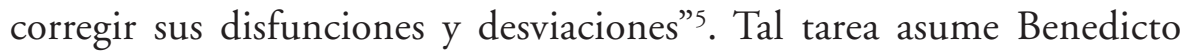
XVI trayendo a juicio las consecuencias de una concepción tecnológica del desarrollo en la esfera de lo político, específicamente en lo que tiene relación con las políticas de protección, la previsión social, los dere-

\footnotetext{
Asociado al proyecto Fondecyt No 1110428 y al "IX Concurso de investigación para académicos UC. Con creatividad, audacia y valentía, maestros por un desarrollo humano integral".

2 En coautoría con Sebastian Neut, Francisca Gómez, Rocío Donoso, Pía Monardes, Karina Stormezan y Verónica Soto.

3 Benedicto XVI, Caritas in Veritate (29 de junio, 2009), No 21.

4 Benedicto XVI, Caritas..., Nº 69.

5 Benedicto XVI, Caritas..., N 32.
} 
chos de los trabajadores y, en general, "para los derechos fundamentales del hombre y para la solidaridad en las tradicionales formas del Estado social"6. La tesis de la imposición de una concepción tecnológica del desarrollo levanta un doble interrogante: ¿es reconocible tal hegemonía en la esfera de las políticas públicas? ¿Qué condiciones debería satisfacer tales políticas para distanciarse de la lógica tecno-económica?

Frente a esa concepción dominante de desarrollo Benedicto XVI actualiza la noción de Desarrollo Humano Integral. Pero para que una categoría ético-social como la de desarrollo humano integral funja al interior de las políticas públicas hace falta contar con formas de observación que den cuenta de la visión de desarrollo que a ellas les dan forma. Ello en tanto que, para que la ética cuente en la esfera pública -sostendrá Kliksberg- se requiere ir más allá del nivel de la filosofía moral y -agregamos por nuestra parte- de la teología moral y de la misma doctrina social de la Iglesia (DSI). Se requiere de una ética en acción ${ }^{7}$, o, para decirlo en términos clásicos, se requiere recorrer en las policies, los caminos de la "razón práctica". La exigencia ética no se obtendrá del esfuerzo de moralización de los policymaker o de los policy managers ${ }^{8}$; urge entonces indagar en "los modos, las maneras prácticas de su encarnación" que el presente artículo tenga como objetivo proponer un dispositivo de observación de la concepción de desarrollo subyacente en políticas públicas a la luz de las tres lógicas propuestas en la Encíclica: la lógica del tener, la lógica del deber y la lógica de la gratuidad.

Las condiciones de posibilidad para plausibilizar teórica y descriptivamente el dispositivo son: (I) la reconstrucción de la trayectoria histórica y conceptual de la noción de desarrollo en su contexto de emergencia; (II) el análisis de las bases conceptuales, especialmente antropológicas, de los principales modelos de desarrollo que se han aplicado o han incidido en el desarrollo de las políticas públicas en Chile y América Latina durante la segunda mitad del siglo XX; (III) el develamiento del tipo de racionalidad subyacente tanto al modelo de desarrollo como al enfoque

6 Benedicto XVI, Caritas..., Nº 25.

7 B. Kliksberg, Más ética. Más desarrollo (Temas, Buenos Aires, 2005).

8 M. Grindle - J. Thomas, Public Choice and policy change. The political economy of reform in developing countries (The Johns Hopkins University Press, Baltimore and London, 1991).

9 P. Salvat, El porvenir de la equidad (LOM, Santiago de Chile, 2002). 
de políticas hegemónico: y (4) la fundamentación teórica y la operacionalización del Desarrollo Humano Integral articulado en las lógicas del tener, del deber y de la gratuidad.

\section{DesarRollo humano: LA EMERgENCIA DE UN CONCEPTO}

La comunidad de expertos concuerda en que el concepto de desarrollo tiene un derrotero semántico que se ha desplegado en el largo plazo. Para Marcel Valcárcel el desarrollo es deudor de la noción de progreso, cuyos orígenes se remontan a la Grecia clásica y cuya consolidación ocurrió durante el periodo de la Ilustración. Otros conceptos que lo han precedido, nos dice este autor, han sido civilización, evolución, riqueza y crecimiento $^{10}$. Una interpretación semejante posee Gilbert Rist, para el que algunos rasgos genético-filosóficos del desarrollo pueden incluso rastrearse en Aristóteles y luego en Agustín ${ }^{11}$. Por su parte, Álvaro Carvajal plantea que "el antecedente más remoto se encuentra en el siglo XVII, con Francis Bacon (1561-1626), quien planteó en su época la necesidad de un nuevo método para hacer una ciencia liberadora de la miseria" ${ }^{2}$. El concepto, continúa, fue recuperado a partir de la noción de progreso, y luego resignificada por autores como Hume, Smith, Malthus, Ricardo, Mill y Marx ${ }^{13}$. De similar opinión es Jorge Larraín, para quien "la idea de desarrollo, tal como la conocemos hoy... no aparece antes del surgimiento del capitalismo y los comienzos de la modernidad"14.

Para Gustavo Esteva el desarrollo surgió en el lenguaje de la biología. Nos dice que entre los siglos XVII y XVIII pasó de designar a cada ser

10 E. VAlCÁrcel, Génesis y evolución del concepto y enfoques sobre el desarrollo. Documento de Investigación (Departamento de Ciencias Sociales Pontificia Universidad Católica del Perú, junio 2006), disponible en: http://www.pucp.edu. pe/departamento/ciencias_sociales/images/documentos/marcel_valcarcel.pdf.

11 G. Rist, The history of development. From western origins to global faith (Sed Books, Londres, 2008).

12 Á. Carvajal Villaplana, "La trama del desarrollo: hacia una noción desarrollada del desarrollo", en Revista de Filosofía Universidad de Costa Rica, 45 (mayodiciembre, 2007), 44.

13 Á. Carvajal Villaplana, "La trama del desarrollo...”, 44.

14 J. Larraín, "Identidad y desarrollo: una tensión sociológica fundamental en el siglo XX”, en Persona y Sociedad, 19, 3, (2005), 48. 
viviente en su "forma apropiada" a su "forma más perfecta"15. En tal contexto, evolución y desarrollo resultaron términos intercambiables. El paso del concepto desde las ciencias naturales a las sociales se produjo en el ambiente alemán en la última parte del siglo XVIII. Para Herder, por ejemplo, el desarrollo histórico era una continuación del natural, y ambos, variantes del desarrollo del cosmos. A principios del siglo XIX el desarrollo se liberó del tutelaje normativo-semántico teológico, al ser considerado una especie de autodesarrollo, en un contexto más amplio en el que "Dios [...] comenzó a desaparecer de la concepción popular del universo" 16 .

Para autores como Anthony Payne y Nicola Phillips ${ }^{17}$, además de Antonio Hidalgo ${ }^{18}$, el surgimiento del concepto de desarrollo debe ser situado junto con la constitución, a fines del siglo XVII o, a más tardar, durante el siglo XVIII, de la economía política, en tanto que ciencia del estudio de la posibilidad de aumentar el bienestar material y riqueza de las naciones, con la cual estaría, si no homologado, al menos empalmado.

El concepto ingresó en la arena de la reflexión política durante el siglo XIX a través de dos variantes. Por un lado, tenemos la reflexión de Marx. Según Schumpeter "el desarrollo es el esquema central de Marx; es uno de los primeros casos en que aparece por primera vez el término desarrollo" 19 . Asimismo para Carvajal, Marx adelantaba ya la reflexión y conceptualización del subdesarrollo, al apelar al colonialismo como una fase avanzada, pero no final, del capitalismo. Otro tanto nos recuerda Esteva, para quien "el desarrollo se convirtió en la categoría central del trabajo de Marx: lo mostró como un proceso histórico que se desenvuelve con el mismo carácter necesario de las leyes naturales" ${ }^{20}$. Por otro lado, el desarrollo fue incorporado como indicador de las políticas del

15 G. Esteva, “Desarrollo", en A. Viola (eds), Diccionario del desarrollo, disponible en: http://es.scribd.com/doc/91345438/Esteva-Gustavo-Desarrollo.

16 G. Esteva, "Desarrollo...".

17 A. Payne - N. Phillips, Desarrollo (Alianza Editorial, Madrid, 2011) 19.

18 A. Hidalgo, "El pensamiento económico sobre desarrollo. De los mercantilistas al PNUD” (1998), disponible: www.uhu.es/antonio.hidalgo.

19 Á. Carvajal Villaplana, "La trama del desarrollo: hacia una noción desarrollada del desarrollo", en Revista de Filosofía Universidad de Costa Rica, 45 (mayodiciembre, 2007) 45.

20 G. Esteva, “Desarrollo...”. 
colonialismo para representar el deber de aquellas naciones o regiones que aún no entraban en la historia de la industrialización, considerada como el epítome del proceso civilizatorio.

Durante el siglo XX el concepto mantuvo, como en una doble filiación, ambas variantes -la crítica y la apologética- incorporadas a su polisemia conceptual, como una especie de rostro de Jano que permitió vehicular distintos e incluso antagónicos proyectos políticos a partir de la misma unidad lingüística.

En la década de 1930 se reafirmaron las relaciones entre desarrollo y colonialismo. A fines de aquella el gobierno británico transformó la Ley de Desarrollo de las Colonias en la Ley de Desarrollo y Bienestar de las Colonias, aduciendo que los habitantes vernáculos debían tener un mínimo de bienestar en salud, educación y nutrición ${ }^{21}$. Por otro lado, la noción de "áreas subdesarrolladas" surgió, sin mucho eco, en 1942, cuando el funcionario de la OIT Wilfred Benson la introdujo para designar a regiones en las que era necesaria una intervención con el objetivo de asegurar la paz de la postguerra.

Sin embargo, la cristalización de una noción de desarrollo nueva, o al menos profundamente reconsiderada, mucho más deslindada de otros conceptos como los de crecimiento, civilización o progreso, se manifestó preclaramente en el "punto 4" del discurso de asunción de la presidencia de Estados Unidos, por segunda vez y de manera consecutiva, por parte de Harry Truman. Varcárcel nos recuerda que el desarrollo "recién adquiere una suerte de legitimidad universal en 1949, cuando el mandatario norteamericano Harry Truman en el discurso de inauguración de su mandato alude a vastas regiones del planeta como mundo subdesarrollado y plantea luchar contra esta situación en el marco del combate al comunismo"22. De la misma opinión es Esteva, para quien Truman inauguró la "era del desarrollo"23. Si bien el recurso a esta noción tiene un derrotero prolongado, la introducción de la tematización trumaniana fue la expresión de, sino un quiebre, una profundización exponencial

\footnotetext{
21 G. Esteva, “Desarrollo...”.

22 E. VAlCÁrCel, Génesis y evolución del concepto y enfoques sobre el desarrollo. Documento de investigación (Departamento de Ciencias Sociales PUCP, junio 2006), disponible en: http://es.scribd.com/doc/71583949/Genesis-y-EvolucionDel-Concepto-de-Desarrollo.

23 G. Esteva, "Desarrollo...".
} 
del desarrollo en tanto que concepto propiamente político ${ }^{24}$, es decir, en tanto que palabra cuya misma densidad semántica proporcionó un amplio horizonte de expectativas humanas que permitieron inteligir, limitar y/o proyectar la experiencia social y personal de múltiples agentes individuales y colectivos. Es precisamente la proyección política del desarrollo "que despegó en aquel momento optimista después de la Segunda Guerra Mundial" 25 lo que resalta como novedoso para Payne y Phillips.

Desde nuestra perspectiva, lo anterior ayuda a explicar el que para muchos autores el mismo recurso al desarrollo en el enmarque del discurso trumaniano, haya generado, en un día y lugar determinados, cierta noción acerca de lo que era y siguió siendo el desarrollo. Así, para Wolfgang Sachs, "el 20 de enero de 1949 [...] de súbito un concepto aparentemente indeleble se estableció, apretando la inmensurable diversidad del sur en una única categoría -el subdesarrollo-" ${ }^{26}$. Y para Esteva, "el 20 de enero de 1949 [...] se abrió una era para el mundo -la era del desarrollo-" 27 . En efecto, en tal discurso, ya se entreveía el marco categorial de un tipo de noción del desarrollo que movilizó enormes energías semánticas y prácticas en, al menos, las restantes décadas del siglo XX.

24 La noción de "concepto político", en tanto que indicador léxico condensador del sentido y del campo de posibilidades de la experiencia, ha sido mayormente trabajado, desde el punto de vista historiográfico, por la denominada "historia conceptual”, cuyo mayor representante ha sido Reinhart Koselleck, y por la denominada "escuela de Cambridge", entre cuyos mejores exponentes se encuentran John Pocock y Quentin Skinner. Algunos ejemplos de trabajos de estos autores son, para el primer caso, R. Koselleck, Futuro pasado. Para una semántica de los tiempos históricos (España, 1993); y para el segundo, J. Pocock. El momento maquiavélico. El pensamiento político florentino y la tradición republicana atlántica (Madrid, 2002), y los dos tomos de Q. Skinner. Los fundamentos del pensamiento político moderno (FCE, 1986). Para una visión integrada de ambas tradiciones pueden revisarse Christian Nadeau, "La historia como construcción social y política. Una lectura combinada de Reinhart Koselleck y Quentin Skinner", en Revista Anthropos: Huellas del conocimiento, 223 (2009), 156-167, y Cristina Moyano, "La historia política en el Bicentenario: Entre la historia del presente y la historia conceptual. Reflexiones sobre la nueva historia política”, en Revista de historia social y de las mentalidades, 15, 1 (2011), pp. 227-245.

25 A. Payne - N. Phillips, Desarrollo..., 19.

26 W. Sachs, Planet dialectics-exploration in environment \& development (Zed Books, Londres, 1999) 28.

27 G. Esteva, “Desarrollo...”. 
Para Truman una nota característica del desarrollo era su directa vinculación con los avances científicos y el progreso técnico de que disponía una nación. Para él, Estados Unidos debía prestar toda la ayuda técnica y científica necesaria para lograr "la mejora y el crecimiento de las áreas subdesarrolladas". Ahora bien, a diferencia de otras nociones políticas, como la de progreso, el desarrollo no se alcanzaría producto de una ley natural de la historia, sino que debía ser coactivado, propulsado y/o impelido. Según Castoriadis "el término 'desarrollo' comenzó a ser utilizado cuando resultó evidente que el 'progreso', la 'expansión', el 'crecimiento' no constituían virtualidades intrínsecas, inherentes a toda sociedad humana, cuya realización (actualización) se habría podido considerar como inevitable, sino propiedades específicas, y poseedoras de un 'valor positivo' de las sociedades occidentales" 28 . En tanto que el desarrollo implicaba una potencialidad no forzosamente consumada, se impuso la planificación como herramienta indispensable para alcanzarlo. Carvajal anota correctamente que "el desarrollo supon[ía] un proceso que es promovido de manera planificada, de ahí la idea de planes y programas de desarrollo" ${ }^{29}$. Ahora bien, la planificación en el enmarque trumaniano era considerada de una manera mínima: bastaba con el fomento de la inversión "en áreas necesitadas de desarrollo" para activar los procesos de desarrollo.

Asimismo, a partir de este momento el concepto adquirió una función denotativa-descriptiva y normativa basal, a saber, indicar una forma de organización político-económica (Estados Unidos, los países ricos) como fáctica-ideal y a su contraparte (los países pobres, subdesarrollados) como fáctica-patológica. Esto permite afirmar complementariamente que "desarrollo y subdesarrollo comenzaron a ser utilizados regularmente por los organismos internacionales como términos explicativos del acrecentamiento de las distancias y diferencias socioeconómicas entre los países ricos del norte y los países pobres del sur"30.

Conectado con lo anterior, en tanto que concepto político, aportó en la unificación, simplificación y categorización de múltiples realidades y contextos sociopolíticos, los que, una vez englobados en las nomenclatu-

28 C. Castoriadis, "Reflexiones sobre el 'desarrollo' y la 'racionalidad', en El mito del desarrollo (Kairós, 1980), disponible en: http://www.fundanin.org/castoriadis7.htm.

29 Á. Carvajal Villaplana, "La trama del desarrollo...", 49.

30 E. VALCÁRCEL, Génesis y evolución.... 
ras de desarrollo y subdesarrollo, pudieron ser sometidos a las profilaxis políticas predefinidas para los respectivos estadios conceptuales. Para Wolfgang Sachs "allí estaba de repente [...] un concepto fundamental que metió la inconmensurable diversidad del sur en una sola categoría: el subdesarrollo. Por primera vez se anunció la nueva visión del mundo: todos los pueblos de la tierra se mueven a lo largo de la misma pista y aspiran a un único objetivo: el desarrollo" ${ }^{31}$. De similar idea es Valcárcel, para el que una nota característica del desarrollo en el cuadro trumaniano es su universalismo, según el cual "existe un modelo único de desarrollo" 32 , y su evolucionismo.

Una idea complementaria fue el espíritu colonialista que animó al desarrollo. Si bien tras la Segunda Guerra Mundial el colonialismo comenzó a retirarse del escenario mundial como manera de establecer relaciones políticas entre países industrializados y países productores de materias primas, las lógicas y estructura de sentir históricas que lo habían animado se reconfiguraron antes que desaparecieron. En los hechos, el desarrollo pudo ser concebido gracias a que "el declive del colonialismo europeo al término de la Segunda Guerra Mundial y la consecuente creación de varios Estados nuevos en África y Asia suscitaron unos problemas políticos, sociales y económicos en un creciente número de países generalmente pobres que proporcionaron un campo rico y atractivo de investigación intelectual" 33 , como nos recuerdan Payne y Phillips. Esto ayuda a explicar el que para el mandatario aludido uno de los argumentos para justificar la introducción de los avances técnicos y científicos de occidente en los países "subdesarrollados" era "ayudarles a darse cuenta de sus aspiraciones para una vida mejor". Este etnocentrismo, que ha sido relevado por Valcárcel y otros autores, apuntala ya no el carácter denotativo-descriptivo del desarrollo originario, sino que su naturaleza prescriptiva-normativa. Es así que en las diferentes teorías del desarrollo no solo se jugó una descripción de las diferentes tipos de sociedades, sino que también cierto carácter normativo que tensionó lo real-histórico en tanto que cotejado con el modelo ideal de desarrollo a ser aplicado. Para el caso, el desarrollo constituyó un modelo político que pasaba por la introducción de materiales técnicos y científicos en los

\footnotetext{
31 W. SACHS, Planet dialectics-exploration..., 3.

32 E. Valcárcel, Génesis y evolución....

33 A. Payne - N. Phillips, Desarrollo, 19.
} 
países pobres, así como inversión que arribaría desde los países desarrollados. El desarrollo, a la vez que programa ya consumado (en los países ricos), era un ideal por consumarse (en los países pobres), para los que los primeros constituían el modelo a seguir.

Finalmente, tal programa fomentaría la tan esperada paz para el mundo de postguerra. Existía, al respecto, una visión bastante esquemática para alcanzar un nuevo estadio de paz mundial después del trauma de dos guerras mundiales. Una de las causas principales de la violencia política y de la expansión del comunismo, según la estructura de sentimiento de los adalides occidentales del desarrollo, era la pobreza que aquejaba a enormes zonas del mundo, la que podía disminuir mediante la inversión y modernización de las sociedades "atrasadas". En consecuencia, la inversión capitalista en naciones pobres constituiría de suyo un acicate poderoso para la generación de un mundo de paz. En palabras de Wolfgang Sachs, "el camino a seguir estaba claro ante los ojos del presidente [Truman]: una mayor producción es la clave para la prosperidad y la paz"34.

ENFoques de Desarrollo y políticas públicas en Chile y AméricA LATINA

Un campo privilegiado de expresión del desarrollo ha sido el de las políticas públicas. La revisión de la literatura especializada permite sostener que durante la segunda mitad del siglo XX en América Latina tales políticas estuvieron asociadas a cinco enfoques de desarrollo que les han dado forma ${ }^{35}$, a saber: el Enfoque Economicista, el de Satisfacción de Necesidades Básicas Insatisfechas (NBI), el del Desarrollo como Expansión de las Libertades, el de Desarrollo Humano del Programa de Naciones Unidas para el Desarrollo (PNUD) y el de Desarrollo Humano Integral.

\section{ENFOQUE ECONOMICISTA}

El denominado modelo o enfoque economicista supone que el indicador determinante del mayor o menor grado de desarrollo de los pueblos es el crecimiento económico, medido especialmente en términos del

34 W. SACHs, Planet dialectics-exploration..., 3.

35 E. Stein - M. Tommasi, "La política de las políticas públicas", en Política y Gobierno, 13, 2, (2006), 393-416. 
Producto Interno Bruto (PIB). De ahí que se sostenga que "los modelos ideológico-económicos preponderantes en Latinoamérica en las últimas décadas han impuesto un concepto estrecho de rentabilidad económica en muchas áreas de la sociedad"36. Proyectado al campo de las políticas públicas, su imperativo viene dado por el manejo estable de los recursos en los niveles macro y microeconómico ${ }^{37}$, de modo que tal administración viene a operar como piedra angular del estadio de desarrollo. De ahí que el análisis económico sea entonces el que predomina en el estudio de los temas públicos vinculados a las políticas públicas" ${ }^{\text {38. Como }}$ presupuesto antropológico de base está el denominado homo economicus, el que actuaría buscando satisfacer sus propios e inmanentes intereses a partir de la toma de decisiones interpretadas como estrictamente racionales y fundadas en la maximización de beneficios y la minimización de $\operatorname{costos}^{39}$. Consecuencia de ello es que las políticas públicas se enfoquen en generar crecimiento del PIB, de los ingresos y de los mercados ${ }^{40}$. Ello conlleva el que, en pos de mantener la senda del crecimiento, resulte plausible el limitar ciertos derechos, como la suspensión temporal de libertades fundamentales y la aceptación de niveles de desigualdad y exclusión social, lo que es argumentado como una consecuencia 'razonable' para el correcto funcionamiento del sistema o como 'sacrificios' sociales que en algún momento serán compensados ${ }^{41}$. En tal perspectiva, el desarrollo "depende en forma sustancial, aunque no exclusiva, de las políticas públicas, especialmente de aquellas que generan una dinámica

36 J. Gutiérrez y E. Moreno, "Desarrollo de las universidades públicas de Latinoamérica: una visión alternativa al modelo economicista de rentabilidad", en Actualidades Investigativas en Educación 10 (2010) 1.

37 M. DÁvila - X. Soto, “¿De qué se habla cuando se habla de políticas públicas? Estado de la discusión y actores en el Chile del bicentenario. Estado, Gobierno, Gestión Pública”, en Revista Chilena de Administración Pública (2011) 16.

38 M. DÁvila - X. Soto, “¿De qué se habla cuando...., 24.

39 W. Parsons, Políticas públicas. Una introducción a la teoría y la práctica del análisis de políticas públicas (FLACSO, México, 2007).

40 K. Vallenas - C. Alza, "Gobernabilidad, Desarrollo y Democracia: un enfoque de derechos humanos en las políticas públicas”, en Revista Derecho y Sociedad de la Universidad Católica y Revista de la Asociación Latinoamericana de Estudiantes de Ciencia Política (2004), disponible en: http://carlosalzabarco.files.wordpress. com/2009/08/articulo-k-vallenas-c-alza-version-final.pdf.

41 K. Vallenas - C. Alza, "Gobernabilidad...”. 
en la sociedad, de innovación, de reducción de costos, de aumento de la riqueza, etc. ${ }^{42}$.

Más allá del autorreferente criterio de este enfoque (el crecimiento genera más crecimiento), surge la duda de si políticas así configuradas podrían ir en contra de la equidad y distribución de las riquezas socialmente producidas al seguir la secuencia canónica: crecimiento económico, pago de la deuda externa, macroequilibrios económicos y desestatización, lo que deja a los públicos de las políticas como variable de ajuste de las imperfecciones del modelo. Con cierto optimismo se sostiene que dicho enfoque de desarrollo y de políticas rápidamente habría superado sus límites "dando lugar a otras dimensiones primordiales del desarrollo que hoy nos permiten gozar de visiones más integrales y complejas” ${ }^{43}$.

\section{Satisfacción de Necesidades Básicas Insatisfechas}

En el cuestionamiento a los límites de la mirada economicista de desarrollo, aparece el enfoque de Satisfacción de Necesidades Básicas Insatisfechas (NBI). Se propone un cambio de foco en el que, desde la secuencia crecimiento, pago de la deuda externa, mantención de macroequilibrios económicos y desestatización, se pasa a un modelo en el que se busca priorizar la identificación y satisfacción de las necesidades básicas no cubiertas. En consecuencia, las acciones del Estado se dirigen a la reducción de estas para el mayor número de personas posible ${ }^{44}$. El ingreso aquí es considerado como una de las variables que determinan la satisfacción de necesidades. Las otras serían "los derechos de acceso a bienes y servicios gubernamentales; la propiedad de activos o patrimonio básico acumulado; el tiempo disponible para la educación, el descanso, la recreación, el trabajo del hogar, y activos no básicos” ${ }^{\prime 5}$. En esta perspectiva, los pobres serán aquellos cuyo consumo no alcanza el umbral de satisfacción de una o más necesidades básicas.

42 C. Larroulet, "Políticas Públicas para el Desarrollo", en Estudios Públicos 91 (invierno 2003) 173.

43 A. Donini, y E. Mealla, Políticas Públicas y Desarrollo (Universidad Nacional de San Martín y Universidad de Complutense Madrid, 2008) 1.

44 K. Vallenas - C. Alza, "Gobernabilidad...".

45 M. Olavarría, Pobreza: conceptos y medidas (Documento de Trabajo N 76, IAP, Universidad de Chile, marzo 2001) 4. 
Este enfoque surgió tras la constatación de la paradoja en la que caía el enfoque economicista, al compatibilizar criterios del desarrollo que pueden determinar simultáneamente aumento del crecimiento y de la desigualdad. Con ello se agudiza la mirada sobre la insatisfacción de necesidades básicas, prestando especial atención a "la dimensión de las carencias o déficits que presentan grupos de población en indicadores o estándares entendidos como básicos de acuerdo a convenciones internacionales" ${ }^{46}$. En este horizonte paradójico, emergió en 1974 la Declaración de Cocoyoc (México): "la esperanza de crear una vida mejor para toda la familia humana ha sido ampliamente frustrada". De ahí que el primer objetivo sería redefinir todo el propósito del desarrollo: este no debería ser 'desarrollar cosas', sino 'desarrollar al hombre', partiendo por sus "necesidades básicas: alimentación, vivienda, vestimenta, salud, educación”. Por su parte, el año 1978 el Banco Mundial comenzó a utilizar el concepto de necesidades básicas, impulsando y promoviendo aquel enfoque, y contribuyendo con ello a instalar una nueva concepción de desarrollo que tenga como norte, la eliminación "de la pobreza, entendida como la insatisfacción de necesidades básicas" ${ }^{47}$. A partir de ello, se estableció un método para los países de Latinoamérica orientado a medir la satisfacción de las necesidades básicas por parte de las personas y sus familias, permitiendo estimar la incidencia de la pobreza y construir perfiles o mapas de pobreza, de los cuales se obtienen datos sobre el acceso a los bienes y servicios básicos que insumen la agenda de las policies.

Desde un punto de vista antropológico este enfoque corre el riesgo de considerar que, una vez satisfechas las condiciones mínimas para el despliegue de la vida personal y social, adviene el desarrollo. Ello se traduce en que el desarrollo al cual apuntan las políticas públicas esté medido por la generación de bienes y servicios, y no por el desarrollo del conjunto de dimensiones en que se juega la realización de la condición humana. Es así que, entre otros, Hidalgo considera que tal enfoque "ca-

46 L. Winchester, "La dimensión económica de la pobreza y precariedad urbana en las ciudades latinoamericanas. Implicaciones para las políticas del hábitat", Instituto Latinoamericano de Planificación Económica Social CEPAL, Naciones Unidas, 2008, p. 29.

47 S. Alkire - E. Santos, Enfoque de NBI y Enfoque de Derechos. Conceptos y Aplicaciones. Curso Técnico de Medición Multidimensional de la Pobreza y sus Aplicaciones (CEPAL, Naciones Unidas, 2010). 
rece de un sustrato teórico importante en que basar todas las políticas de satisfacción de las necesidades básicas" ${ }^{38}$. Por su parte, Streeten aporta a la discusión del enfoque levantando algunos puntos ciegos del mismo: (1) quién define las necesidades; (2) si la meta es "el florecimiento humano" o "la satisfacción de las necesidades básicas"; (3) cuál es el papel de la participación; (4) cuáles son las necesidades que las instituciones pueden legítimamente planear satisfacer; y (5) cómo coordinar los recursos internacionales para satisfacer las necesidades básicas ${ }^{49}$.

\section{Desarrollo como Expansión de las Libertades}

Un tercer enfoque considera al desarrollo como los grados de libertad que alcanzan las personas de un país. En ese marco las políticas públicas consideran que aquel se alcanza cuando las personas logran ser lo que quieren ser. Este enfoque encuentra sus bases en los planteamientos de Amartya Sen, quien comprende a la democracia como un valor universal y al desarrollo como "un proceso de expansión de las libertades reales de las que disfrutan los individuos" ${ }^{\circ}$, en el que estas pueden definirse como medios y fines del mismo desarrollo. En otras palabras: el disfrute de la libertad es el objetivo del desarrollo, en tanto que el incremento de esta opera como medio para su más plena expresión, cuestión que, por tanto, incrementa el desarrollo. En consecuencia, el desarrollo económico, si bien puede aportar al proceso de expansión de las libertades humanas, jamás será el objetivo final de un pleno desarrollo, pues "no es suficiente fijarse como objetivo básico la maximización de la renta o de la riqueza que, como señaló Aristóteles, no es más que un instrumento para con-

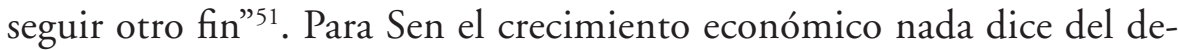
sarrollo si no se observa aquello que se haga con la riqueza de un país, o mejor aún con las capacidades que tengan las personas en hacer aquello que ellas quieran con la riqueza para tener una mejor calidad de vida. Aquí las políticas tienen un horizonte a la vez que un límite: el horizonte de la libertad y el límite que les imponen las formas de vida que elijan

\footnotetext{
48 A. Hidalgo "El pensamiento económico..." 237.

49 P. Streeten “Basic needs: some unsettled questions”, en R. Mogrovejo Desarrollo: enfoques $y$ dimensiones (s.f.), disponible en http://www.cebem.org/cmsfiles/ publicaciones/Desarrollo.pdf

50 A. Sen, Desarrollo como Libertad (Editorial Planeta, Madrid, 2000).

51 K. Vallenas - C. Alza, "Gobernabilidad...”.
} 
los ciudadanos. Un desarrollo que se basa en la libertad, justamente por esto, permite a los individuos aumentar las capacidades para vivir de la forma en que quieran vivir, auténtica meta del desarrollo. Sentenciará Sen: "si el fin es centrar la atención en las oportunidades reales del individuo para alcanzar sus objetivos habría que tener en cuenta no solo los bienes primarios que poseen las personas sino también las características personales relevantes que determinan la conversión de los bienes primarios en la capacidad de la persona para alcanzar sus fines" 52 . Ello va más allá de la satisfacción de las necesidades básicas, proyectándose a la posibilidad y libertad para participar personal y socialmente en la economía, a la libertad de expresión y participación política, una educación y salud de calidad, así como formas de protección contra el desempleo. Además Sen ve a la persona como un agente activo de los procesos de desarrollo que experimenta. Es decir, que corresponde al motor de cambio que hace funcionar las capacidades que se convertirán en libertades, y con esto el desarrollo es un logro asociado a una actitud activa y no pasiva de las personas en las políticas que las afectan.

\section{Desarrollo Humano según el PNUD}

El enfoque anteriormente expuesto sirve de base para una cuarta conceptualización sobre desarrollo: el Desarrollo Humano, que ha dado origen al extendido Índice de Desarrollo Humano aplicado en todo el mundo por el Programa de Naciones Unidas para el Desarrollo (PNUD). Este nació como resultado de las críticas crecientes al enfoque predominante en la década de 1980, el cual consideraba como sinónimos crecimiento económico y desarrollo, lo que produjo que "el nexo entre mayor producto y menor pobreza se considerara tan fuerte que muchos economistas estaban convencidos de que bastaba centrarse exclusivamente en el crecimiento para alcanzar el objetivo último de desarrollo"53. Ante tal situación, surge este enfoque que comprende al desarrollo no solo como crecimiento económico, sino que coloca al centro a las personas y su desenvolvimiento personal, considerándose el desarrollo humano como

52 A. SEN, "Democracy as a Universal Value", en Journal of Democracy 10/3 (1999).

53 K. Griffin, Desarrollo humano: origen, evolución e impacto (2001), disponible en: http://otrodesarrollo.com/desarrollohumano/GriffinDesarrolloHumano.pdf, 1. 
un "cambio radical de paradigma en el pensamiento del desarrollo" 54 . Cambio que se materializó de la mano de las ideas centrales de Amartya Sen. Este enfoque promociona y fortalece el desarrollo potencial de las personas, aumentando sus posibilidades y disfrute de la libertad para vivir la vida que desean y valoran, la cual está mediada por la cantidad de opciones que tienen y son utilizadas para hacer y ser lo que la persona desea; de ahí la importancia del desarrollo de las capacidades humanas. De ahí se impone un límite para la intervención del Estado, al que solo le compete generar o potenciar las condiciones para que las oportunidades que deben tener las personas se desarrollen.

Probablemente el mayor impacto de esta concepción reside en el establecimiento de un Índice de Desarrollo Humano que permite jerarquizar los países del mundo. Operacionalizando las dimensiones económicas, salud y educación asigna una valor cero a la total ausencia de desarrollo y uno a su plena satisfacción. No obstante que para este enfoque el desarrollo humano solo es posible cuando existe una "libertad democrática" 55 , llama la atención el que en su mensuración está ausente la dimensión política. Siendo paradójicamente posible que un país donde no se respeten los derechos fundamentales alcance un alto nivel en el IDH.

\section{Desarrollo Humano Integral}

Un quinto enfoque que alude a un desarrollo alternativo a los ya tratados, es el denominado modelo alternativo del desarrollo humano integral. Propuesta la categoría de desarrollo humano integral por Pablo VI en Populorum Progressio (1967) como clave para el progreso de los pueblos, como nuevo nombre de la paz, como el paso de condiciones de vida menos humanas a condiciones de vida más humanas, sentó las bases para pensar alternativas que incorporen las diversas esferas de la vida de las personas y los pueblos en una perspectiva de integralidad y humanización. Entre quienes promueven este enfoque en la esfera pública en América Latina se hace expresa referencia a esta categoría surgida en el desarrollo de la DSI. Recientemente esta categoría ha sido revisitada por

54 S. Deneulin, The capability approach and the praxis of development (Houndmills, Palgrave Macmillan, 2006).

55 PNUD, Informe sobre el Desarrollo Humano: concepto y medición del desarrollo humano (PNUD, Santiago de Chile, 1990). 
Benedicto XVI en su encíclica social Caritas in Veritate (CIV), después de la que de ella hiciera Juan Pablo II en Sollicitudo rei Socialis (1987). En un escenario de profundas transformaciones socioculturales, políticas y económicas asociadas al proceso de globalización, Benedicto XVI, junto con rendir homenaje y honrar la memoria de Pablo VI, se propone actualizar su enseñanza sobre el desarrollo humano integral, bajo la convicción de que la Populorum Progressio merece ser considerada como "la Rerum Novarum de la época contemporánea" ${ }^{56}$.

Inspirado en tales planteamientos de la Doctrina Social de la Iglesia surge en América Latina un movimiento que pretende proyectar este concepto a la esfera pública en la realidad actual del continente. El enfoque alternativo de desarrollo humano integral trata de promover una "opción radicalmente humanizadora frente a toda reducción técnicoinstrumental" 57 , basada en la idea del compartir como una "relación de "apertura y entrega" del sujeto al reclamo de humanidad proveniente de todo semejante adolorido y discriminado, hecho prójimo interpelante de respeto y acogida" ${ }^{58}$. Con ello demanda el considerar a las personas y usuarios de políticas públicas "en el centro del proceso de desarrollo" 59 . De esta manera son las personas las protagonistas de su desarrollo, potenciando así la participación de la sociedad civil en los procesos de formulación de políticas públicas, de manera tal que se desarrolle un proceso de autogestión de lo político y lo social. Es un proceso a través del cual los individuos y las organizaciones de base e intermedias deben reasumir actividades, derechos y espacios de decisión que se han concentrado en Estados, generalmente burocratizados y excesivamente centralizados ${ }^{60}$.

Modelo ECONOMicista DE DESARROLlo y MODELO RACIONAL DE ANÁLISIS DE POLÍ́TICAS PÚBLICAS

Del mismo modo que los enfoques de desarrollo dan forma a las políticas públicas, es posible afirmar que sus diversos modelos de análisis

\footnotetext{
56 Benedicto XVI, Caritas... No 8.

57 Benedicto XVI, Caritas... No 8.

58 Benedicto XVI, Caritas... No 8.

59 Benedicto XVI, Caritas... No 8.

60 Benedicto XVI, Caritas... No 8.
} 
(racional, de elites, de grupos, institucional, incremental, entre otros) vehiculan una noción subyacente de desarrollo. Se propone a continuación un ejercicio de develamiento de la noción de desarrollo presupuesta en el modelo racional -uno de los modelos de análisis predominantes en el ámbito de las policies-, a partir del ángulo de acercamiento del tipo de racionalidad subyacente a ambos. En los hechos, se reconoce una relación de afinidad electiva entre tal modelo y uno de los enfoques de desarrollo dominantes en América Latina: el economicista. En este marco, lo que se busca responder a la pregunta por la aplicación de la crítica a la concepción tecnológica del desarrollo que realiza Benedicto XVI en la encíclica Caritas in Veritate al concepto de desarrollo subyacente en modelos de análisis de políticas dominantes en Chile. En el análisis de las políticas el foco está puesto en el proceso de toma de decisiones. Al decir de Parsons, este análisis está "relacionado con el uso de diversas técnicas para mejorar (o racionalizar) el proceso de toma de decisiones" ${ }^{61}$. En el caso del modelo racional, nace con una vocación claramente descriptiva, teniendo como objetivo el uso del análisis científico para solucionar problemas públicos, optimizar recursos disponibles y garantizar resultados políticos a partir de la acción planificada definida por grupos de expertos.

Pero no es cualquier tipo de racionalidad sobre la que se construye este modelo. Sus principales fuentes son dos: la idea de racionalidad económica, tal como se desarrolló en la teoría económica clásica, y la idea de racionalidad burocrática, tal como fue formulada por las teorías sociológicas de la organización y la sociedad industrial. De aquí se deriva que el uso de la racionalidad en las políticas públicas tiene sus raíces en la construcción del hombre económico -como ya veíamos a propósito del enfoque de desarrollo economicista- que busca satisfacer sus propios intereses y tomar decisiones a partir de la recolección de información, la comparación de las alternativas disponibles y la elección de aquella que le permita alcanzar a los menores costos y esfuerzo sus objetivos. El modelo racional de análisis de política pública, confía el proceso de formulación de la policy a un determinado tipo de racionalidad (ethos ilustrado) que busca "investigar la naturaleza, las causas y los efectos de las distintas alternativas disponibles para la solución de un problema de política, con el fin explícito de influenciar de forma más o menos

61 W. Parsons Políticas públicas. Una introducción... 
directa el proceso de selección de las alternativas"62. De ahí que tres de los elementos centrales de este modelo sean la primacía de los expertos en la formulación de políticas públicas, el énfasis en el análisis tecnocientífico y cierta confianza en la capacidad exitosa de una planificación paradojalmente apolítica.

En el caso del modelo racional, se parte del supuesto de que la concentración de la toma de decisiones en grupos de expertos que cuentan con el "conocimiento técnico" adecuado puede definir, a partir de una racionalidad técnica también experta, los programas de acción gubernamental de forma objetiva y eficiente, presuponiéndose la existencia de un decisor racional que tiene la capacidad de definir los objetivos y preferencias sobre un problema público concreto. El poder de toma de decisiones queda entonces en manos de una reducida y selecta subclase de prohombres que presumirían conocer cómo funciona la sociedad y cuáles son las necesidades y deseos de los diferentes agentes sociales, sobre todo los de los grupos menos visibles y más influenciables. A su vez, el enfoque economicista considera el desarrollo como un resultado calculable y gestionable desde una racionalidad experta que ajusta medios a fines puramente pragmáticos.

En relación al concepto de desarrollo, es interesante observar que, particularmente después de la Segunda Guerra Mundial, la toma de decisiones queda en manos de determinados países (desarrollados) que cumplen la función de los grupos de expertos que definen aquello que se entenderá por desarrollo y las "vías" de su concreción para aquellos países "subdesarrollados" o "en vías de desarrollo". Payne y Phillips reconocen sin embargo, que a su llegada, el desarrollo no era solo un proyecto técnico sino principalmente un proyecto político, es decir, "un programa de cambio que debían seguir los 'países en desarrollo' alentados por los 'países desarrollados"'63. En este contexto, la idea de Chaqués de que lo único que deben hacer los Estados "es dejarse asesorar por estos grupos de expertos-científicos, e intentar que la política (la deliberación

62 G. Regonnini, El estudio de las politicas públicas, en P. Miranda - A. Razeto "Figuras de Políticas. Diferenciación social y normativa en modelos de análisis de políticas públicas", Santiago de Chile, s/e.

63 A. Payne -N. Phillips, Desarrollo...19. 
y el debate) ocupe el menor espacio posible en el proceso" ${ }^{\text {, }}$, aplica tanto para la formulación de políticas públicas, como para la adopción de modelos de desarrollo.

Vislumbrada en la anterior idea, se erige una noción de ciencia tal que calza con la interpretación que de ella lúcidamente realizó Karl Rahner ${ }^{65}$, según la cual solo ella estaría en el mundo sin saturación ética -sin mundo-y podría a la vez conocerlo tal como es (el mundo no se conoce ni reconoce). En la concepción racionalista queda implícito el supuesto de que lo científico es 'lo' objetivo y está exento de juicios de valor, por lo que la figura del experto invoca no solo la idea de quien posee el saber y por tanto el poder de actuar técnica (y políticamente), sino de quien lo hace desde la mentada neutralidad valorativa. En el modelo racional de análisis de política, el policy maker opera con la weberiana pretensión de 'neutralidad valorativa', en virtud de la cual los métodos y los instrumentos de análisis de políticas se piensan como "instrumentos neutros que pueden ser usados por analistas que son imparciales y están distanciados de los problemas de las políticas" ${ }^{36}$. A su vez, en el modelo de desarrollo economicista se releva un tipo de racionalidad que se pregunta por el "cómo" a la vez que (astutamente) ocluye el "por qué", lo que al decir de Benedicto XVI "puede alentar la idea de la autosuficiencia de la técnica" ${ }^{67}$. De ahí su constitutiva ambigüedad que lleva a considerar el desarrollo "con frecuencia como un problema de ingeniería financiera, de apertura de mercados, de bajadas de impuestos, de inversiones productivas, de reformas institucionales, en definitiva como una cuestión exclusivamente técnica" 68 .

Si en este se impone el cientificismo como saber, su correlato en el nivel político es la prevalencia de una especie de régimen de planificación recortado sobre el profundo y anguloso fondo de la sociedad. La racionalidad técnica implica asumir la idea de la unicidad del método, lo

64 L. Chaqués, Redes de políticas públicas (CIS- Siglo XXI Editores, Madrid, 2004) 108.

65 K. Rahner, Teología y ciencias naturales (Taurus, Madrid, 1967).

66 S. Çelık - S. ÇorbacioğLu, "Sosyal Bilimler Dergisi” en P. Miranda - A. Razeto, "Figuras de Políticas..."

67 Benedicto XVI, Caritas... No 70.

68 P. Miranda, "Caritas in Veritate: una relectura actualizante del desarrollo integral", en Revista Católica, 109/1163 (2009). 
que volcado a nuestro análisis significa que en el modelo racional existe una sola forma de aproximación a los problemas públicos, entendiendo la política pública como 'receta' aplicable a los distintos contextos sociales, políticos, económicos y culturales. En este punto podemos hacer alusión a las ideas de Osman, quien hace mención de la diferencia que existe en el proceso de elaboración de políticas entre países desarrollados y países en desarrollo, señalando que las teorías existentes del policymaking son de utilidad para el análisis de políticas de países en desarrollo pero no son suficientes para llevar a cabo un análisis comprensivo de las mismas, "y esto se debe a que la mayoría de las teorías del policymaking han sido derivadas de estudios de sociedades industrializadas desarrolladas que, en la mayoría de los casos, son consideradas insuficientes para explicar las políticas de los países en desarrollo debido a las variaciones contextuales" ${ }^{\prime \prime}$.

Asimismo, el modelo tecnoeconómico de formulación de políticas elude "los pasos del debate, negociación, aprobación y ejecución" ${ }^{\text {, }}$, de la mano de las políticas de desarrollo imperantes en Chile y América Latina deudoras del Consenso de Washington, que consistieron justamente en pretender no tener ninguna política. Dicho consenso fijó las claves para el desarrollo económico en mercados libres y una moneda sólida de modo que la política dominante pasó a ser el no tener política y confiar al mercado la distribución de los recursos. Esta pretensión de «apoliticismo» fue abandonada bajo el nuevo énfasis en la «buena gobernanza" propuesta -o impuesta- por el Banco Mundial, que dio licencia para intervenir masivamente y en términos marcadamente políticos en los países en desarrollo, sin embargo, afirman Payne \& Phillips, en un sentido distinto, el espíritu 'apolítico' de las estrategias de desarrollo neoliberales se mantuvo y perpetuó, basándose la agenda de la nueva gobernanza en la llamada 'ilusión tecnicista', es decir, "la errónea convicción de que existe siempre un posible 'ajuste técnico, administrativo o de gestión para los problemas de desarrollo'”71. Así también, existiría una sola forma de desarrollo, donde el referente lo constituyen los países industrializados del norte a los que solo haría falta seguir en su camino

69 F. Osman, "Public policy making: theories and their implications in developing countries", en Asian Affairs (2002) 37.

70 E. Stein - M. Tommasi, "La política de las políticas públicas" 4.

71 A. Payne - N. Phillips, Desarrollo, 123 
ya recorrido (cuestión que además haría más fácil tal tránsito). Esta noción de desarrollo criticada por Benedicto XVI corresponde a una que, de la mano de la imagen científica de mundo, confía todo el proceso del desarrollo solo a la técnica, privándolo de este modo de su posibilidad de ser configurado por la razón práctica. Es decir, hacer política, y no hacer políticas sin política.

A la luz del análisis desarrollado, es posible afirmar que un nudo gordiano de encuentro entre la concepción tecnológica o economicista del desarrollo y el modelo racional, lo constituye el tipo de racionalidad que subyace a ambos: la racionalidad instrumental, donde lo que importa es la relación medio-fin. Por lo tanto, la crítica que elabora Benedicto XVI a la concepción tecnológica del desarrollo podría ser perfectamente aplicada al modelo racional de análisis de política pública y al concomitante enfoque de desarrollo economicista, lo que lleva al interrogante de "por qué las decisiones de tipo técnico han funcionado hasta ahora solo en parte" 72 .

Desarrollo Humano Integral y políticas públicas: del concepto A SU MENSURACIÓN

Sobre la base de lo ganado en la problematización del concepto de desarrollo, es que nos adentramos ahora a proponer un dispositivo de observación del grado de desarrollo humano integral, reconocible en el proceso de políticas, a la luz de una lectura de los aportes que Benedicto XVI propuso en Caritas in Veritate.

Puesto en contraste con el dominante dispositivo de observación y normalización, el Índice de Desarrollo Humano (IDH) creado por $\mathrm{Na}$ ciones Unidas, impone de entrada una diferencia sustantiva: allí donde el IDH se construye sobre la base del individuo y las mayores o menores posibilidades que cada nación ofrece para expandir el radio de sus elecciones, el Índice de Desarrollo Humano Integral (IDHI) aquí propuesto se funda en una idea del ser humano que, sin desconocer su individualidad, sitúa esta en una constelación constitutivamente relacional: "La revelación cristiana sobre la unidad del género humano presupone una interpretación metafísica del humanum, en la que la relacionalidad es

72 Benedicto XVI, Caritas... No 71. 
elemento esencial"73. Es así que cualquier mensuración del desarrollo humano integral al modo en que se lo concibe en CIV deberá reflejar la antropología relacional que se propone en la encíclica.

Como ya quedó dicho y lo hemos desarrollado en otros trabajos, la categoría de desarrollo humano tiene una intrínseca carga axiológica y normativa ${ }^{74}$. Sirve como criterio contrafáctico para juzgar el presente, develando anticipaciones y negaciones, a la vez que sirve como idea reguladora en tanto proyecta un futuro deseado. En el campo de las políticas públicas, ello dice del referencial normativo desde donde se define qué es un problema público y cuál es el deber ser que habrá de ser intencionado a través de ellas. Puesto en la escena del surgimiento del concepto, tal como se mostró en la primera parte, la incorporación del concepto de desarrollo en la DSI pasó por un proceso de resignificación. Frente a las teorías del desarrollo existentes a la fecha, que le otorgaban una significación prevalentemente económica, Juan XXIII va a adjetivar la expresión para mejor reflejar de manera inequívoca el aporte original que la Iglesia busca hacer desde su comprensión de lo humano. Para que el desarrollo sea considerado integral es menester evitar la reducción economicista del concepto. Pablo VI indicará por su parte que "el desarrollo no se reduce al simple crecimiento económico"75, ya sea derivado del orden espontáneo del mercado autorregulado o del despliegue de un modelo de economía centralmente planificada. Una teoría axiológica y normativa como la DSI no puede complacerse en la cuantificación del crecimiento económico como indicador del desarrollo de los pueblos. Para que sea tal debe satisfacer una exigencia antropológica: promover a todos los hombres y a todo el hombre ${ }^{76}$. Tanto este epítome como aquel de que el desarrollo es el nuevo nombre de la paz, evocan con fuerza el imperativo moral, individual y colectivo, de trabajar constantemente por el desarrollo de los hombres y pueblos ${ }^{77}$. Benedicto XVI aporta a la resignificación del concepto proyectándolo en el telón de tres lógicas

Benedicto XVI, Caritas... No 55.

74 P. Miranda, “¿Desarrollo Integral o prejuicio humanista?: Una problematización de supuestos en la doctrina social de la Iglesia”, en revista Teología y Vida, 48/1 (2007).

75 Pablo VI, Populorum Progressio (26 de marzo, 1967) N 14.

76 Pablo VI, Populorum... No 14.

77 Pablo VI, Populorum... No 14. 
que articulan las relaciones sociales, tanto a nivel micro como macro: la lógica del tener, la lógica del deber y la lógica de la gratuidad. Pero tal resignificación habrá de recorrer los caminos de la razón práctica en la esfera pública si ha de buscar incidir en la configuración de lo público.

\section{LA LÓGICA DEL TENER}

Con la lógica del tener, junto con reconocer el imperativo existencial de un ser necesitado de bienes y servicios - de hecho una parte importante de los bienes que las policies intencionan apuntan a la posibilidad de la reproducción material de la vida-, se busca la satisfacción de derechos fundamentales exigidos para la vida digna. En este sentido no se puede hablar de desarrollo humano integral cuando esta esfera del tener que compromete el ser, no es satisfecha. En términos tomasianos sería como pretender desarrollar las virtudes sin el mínimo material requerido para ello. El derecho a la alimentación, al agua, al vestido, a un trabajo decente, entre otros, son imperativos que un auténtico desarrollo vehicula y exige. Si a un nivel ontológico el ser precede al tener, lo que se declina a nivel antropológico en la primacía del ser más por sobre el tener más, es que precedencia no implica prescindencia. Es así que desde esta lógica, las políticas públicas de una nación deben ser interrogadas en su conjunto en función de qué tanto crean efectivas condiciones de posibilidad para la satisfacción de tales derechos primordiales. Es exigencia de justicia -mediación operativa de la caridad- el reconocimiento y respeto de los derechos de las personas y los pueblos: "la caridad exige la justicia, el reconocimiento y el respeto de los legítimos derechos de las personas y los pueblos" 78 . Por su parte, el bien común como otra mediación operativa de la caridad, reclama el cuidar "ese conjunto de instituciones que estructuran jurídica, civil, política y culturalmente la vida social, que se configura así como polis, como ciudad"79, de tal modo que la lógica de la gratuidad se torna tanto más eficaz cuanto "más se trabaja por un bien común que responda también a sus necesidades reales" ${ }^{" 0}$.

El riesgo de reducción a la lógica del tener es resaltado en la CIV en contraste con una visión unidimensional de la persona humana, en

\footnotetext{
78 Benedicto XVI, Caritas... N ${ }^{\circ} 6$.

79 Benedicto XVI, Caritas... No 8.

80 Benedicto XVI, Caritas... No 8.
} 
tanto se sostiene que "el auténtico desarrollo del hombre concierne de manera unitaria a la totalidad de la persona en todas sus dimensiones" ${ }^{\prime 1}$. Este riesgo se actualiza cada vez que la comprensión de la realización de lo humano se reduce "solo al incremento del tener»" "Pablo VI tenía una visión articulada del desarrollo. Con el término «desarrollo» quiso indicar ante todo el objetivo de que los pueblos salieran del hambre, la miseria, las enfermedades endémicas y el analfabetismo. Desde el punto de vista económico, eso significaba su participación activa y en condiciones de igualdad en el proceso económico internacional; desde el punto de vista social, su evolución hacia sociedades solidarias y con buen nivel de formación; desde el punto de vista político, la consolidación de regímenes democráticos capaces de asegurar libertad y paz" ${ }^{33}$.

Es así que una determinada política que se configure a la medida de una red de individuos que en y a través de ellas solo busquen la maximización de sus propios intereses, invierte -a la vez que pervierte- tanto la prioridad del ser sobre el tener, como el interés por ese bien del nosotros -bien común le llama Benedicto XVI- que viene exigido por una antropología relacional. Una política así operante, dicho en términos habermasianos, es una política colonizadora de los mundos de vida en tanto ejerce violencia con la lógica del tener sobre los vínculos de solidaridad introyectando una normatividad de tipo preconvencional que induce lógicas de competencia en el horizonte de la maximización de los juegos de intereses individuales. Esto no significa que el tener de suyo implique preconvencionalidad, sino solo cuando la lógica del tener es hegemónica, cuando el tener se homologa predominantemente al juego de intereses particulares (doy para dar). Se da así origen a un tipo de relación de intercambio mercantil basado en la regla de equivalencia entre lo dado y lo recibido, dando como resultado aquello que Benedicto XVI observa en CIV: "La gratuidad está en su vida de muchas maneras, aunque frecuentemente pasa desapercibida debido a una visión de la existencia que antepone a todo la productividad y la utilidad" ${ }^{\prime 2}$.

\footnotetext{
81 Benedicto XVI, Caritas... No 11.

82 Benedicto XVI, Caritas... N ${ }^{\circ} 11$.

83 Benedicto XVI, Caritas... No 21.

84 Benedicto XVI, Caritas... N ${ }^{\circ} 34$.
} 


\section{LA LÓGICA DEL DEBER}

En perspectiva del desarrollo humano integral la categoría de lo justo, a la que remite la lógica del deber, es propuesta como una dimensión operativa de la lógica de la gratuidad. La justicia es mediación de la lógica gratuidad no obstante que la caridad va más allá de la justicia, porque amar es dar, ofrecer de lo 'mío' al otro; pero nunca carece de justicia, la cual lleva a dar al otro lo que es 'suyo', o que le corresponde en virtud de su ser y de su obrar. No puedo 'dar' al otro de lo mío sin haberle dado en primer lugar lo que en justicia le corresponde. "Quien ama con caridad a los demás, es ante todo justo con ellos" 85 .

En la lógica del deber ahora, se pueden diferenciar dos ámbitos: uno derivado de la función asignada a los diversos actores, es decir, una moralidad recortada completamente a la medida del solo cumplimiento de roles y funciones atingentes al cargo (expectativas de rol), y otro derivado ámbito donde la moralidad queda reducida al orden legal vigente. Es decir, quien cumple de manera superlativa las expectativas de rol es considerado como un meritante; el problema es cuando el límite y sentido es puesto allí, lo que tiende a una oclusión de la sobreabundancia propia de la lógica del don. Dirá Benedicto XVI: "Por su naturaleza, el don supera el mérito, su norma es sobreabundar" ${ }^{\prime 6}$. Una política que tenga que ver con el virtuosismo de cumplir con el deber no está en la lógica del don, que es anterior al mérito.

\section{LA LÓGICA DE LA GRATUIDAD}

Tal como señala Benedicto XVI, "La 'ciudad del hombre' no se promueve solo con relaciones de derechos y deberes sino, antes y más aún, con relaciones de gratuidad, de misericordia y de comunión" ${ }^{\prime 7}$. En los niveles más altos de moralidad un actor clave es la sociedad civil, que corresponde al bien de ese "todos nosotros"; como señala el pontífice: "Amar a alguien es querer su bien y trabajar eficazmente por él. Junto al bien individual, hay un bien relacionado con el vivir social de las personas: el

\footnotetext{
85 Benedicto XVI, Caritas... Nº 6.

86 Benedicto XVI, Caritas... N 34.

87 Benedicto XVI, Caritas... Nº 6.
} 
bien común. Es el bien de ese «todos nosotros», formado por individuos, familias y grupos intermedios que se unen en comunidad social" $"$.

Podemos preguntarnos de qué manera la política pública cautela "formas internas de solidaridad y de confianza recíproca", y de qué manera las promueve o no. En la exigencia trascendental de la comunicación hay un piso previo que es la gratuidad, es el don en tanto la praxis comunicativa no redunda por sí sola en fomento de la fraternidad. Es así que si el desarrollo económico, social y político quiere ser auténticamente humano, ha de "dar espacio al principio de gratuidad como expresión de fraternidad" 89 . La fraternidad debe ir contenida en los procesos y los productos: "Considero -nos dice Benedicto XVI haciendo suya la posición de Juan Pablo II- que la sociedad civil era el ámbito más apropiado para una economía de la gratuidad y de la fraternidad, sin negarla en los otros dos ámbitos [a saber, el mercado, del que depende la lógica del tener, y el Estado, del que lo hace en relación a la lógica del deber]. Hoy podemos decir que la vida económica debe ser comprendida como una realidad de múltiples dimensiones: en todas ellas, aunque en medida diferente y con modalidades específicas, debe haber respeto a la reciprocidad fraterna" ${ }^{\prime \prime}$.

Como continúa señalando, "el principio de gratuidad y la lógica del don, como expresiones de fraternidad, pueden y deben tener espacio en la actividad económica ordinaria" ${ }^{11}$, pero no solo en ella sino también en el espacio de las políticas públicas, agregamos por nuestra parte. Para ello "es necesaria la movilización efectiva de todos los sujetos de la sociedad civil, tanto de las personas jurídicas como de las personas físicas" Más aún: "los proyectos para un desarrollo humano integral no pueden ignorar a las generaciones sucesivas, sino que han de caracterizarse por la solidaridad y la justicia intergeneracional"93.

Podemos afirmar ahora que una expresión de los habermasianos estadios de moralidad superiores estaría en el vínculo entre la lógica de la

\footnotetext{
88 Benedicto XVI, Caritas... N ${ }^{\circ} 7$.

89 Benedicto XVI, Caritas... N 34.

90 Benedicto XVI, Caritas... No 38.

91 Benedicto XVI, Caritas... N ${ }^{\circ} 36$.

92 Benedicto XVI, Caritas... No 47.

93 Benedicto XVI, Caritas... N $N^{\circ} 4$.
} 
gratuidad y el primado de la sociedad civil. En el campo de las políticas públicas, indicador o no de ello, sería la existencia de procesos de deliberación de la sociedad civil en los asuntos públicos que les conciernen y afectan. Ello diría del reconocimiento del otro como un legítimo otro. Desde la lógica de la gratuidad es posible afirmar que en tanto la caritas implica el amor a otro por sí mismo, es decir, la afirmación del otro bajo la afirmación de fin y no de simple medio, hay una primera precondición cual es el reconocimiento del otro en su dignidad y derechos como criterio anterior y superior a la lógica del tener y a la del deber. En el nivel de los principios éticos universalistas, se reconoce al otro como sujeto de derecho, es decir, estamos en el camino de la gratuidad.

\section{Dispositivo DE OBSERVACIÓN DEL DHI}

A partir de los elementos desplegados sobre las lógicas del tener, del deber y de la gratuidad, se propone un dispositivo de observación que, llevado a un escalamiento tipo Lickert -con polaridades muy en desacuerdo (MD) y muy de acuerdo (MA), y con los grados intermedios en desacuerdo pero no del todo (D), ni de acuerdo ni en desacuerdo (A/D) y de acuerdo pero no del todo (A)-, adquiere la siguiente forma:

\section{Cuadro $\mathrm{N}^{\circ} 1$}

Dispositivo de observación de DHI

\begin{tabular}{|l|l|l|l|l|l|l|}
\hline Dimensión & \multicolumn{1}{|c|}{ Reactivo } & MD & D & A/D & A & MA \\
\hline $\begin{array}{l}\text { Lógica del } \\
\text { tener }\end{array}$ & $\begin{array}{l}\text { En su conjunto, las políticas } \\
\text { públicas crean o favorecen las } \\
\text { condiciones efectivas de posi- } \\
\text { bilidad para la satisfacción de } \\
\text { derechos básicos (alimentación, } \\
\text { abrigo, agua, etc.) }\end{array}$ & & & & & \\
\hline & $\begin{array}{l}\text { En su conjunto, las políticas pú- } \\
\text { blicas no dejan la satisfacción de } \\
\text { derechos básicos a las solas 'leyes } \\
\text { del mercado'. }\end{array}$ & & & & & \\
\hline
\end{tabular}




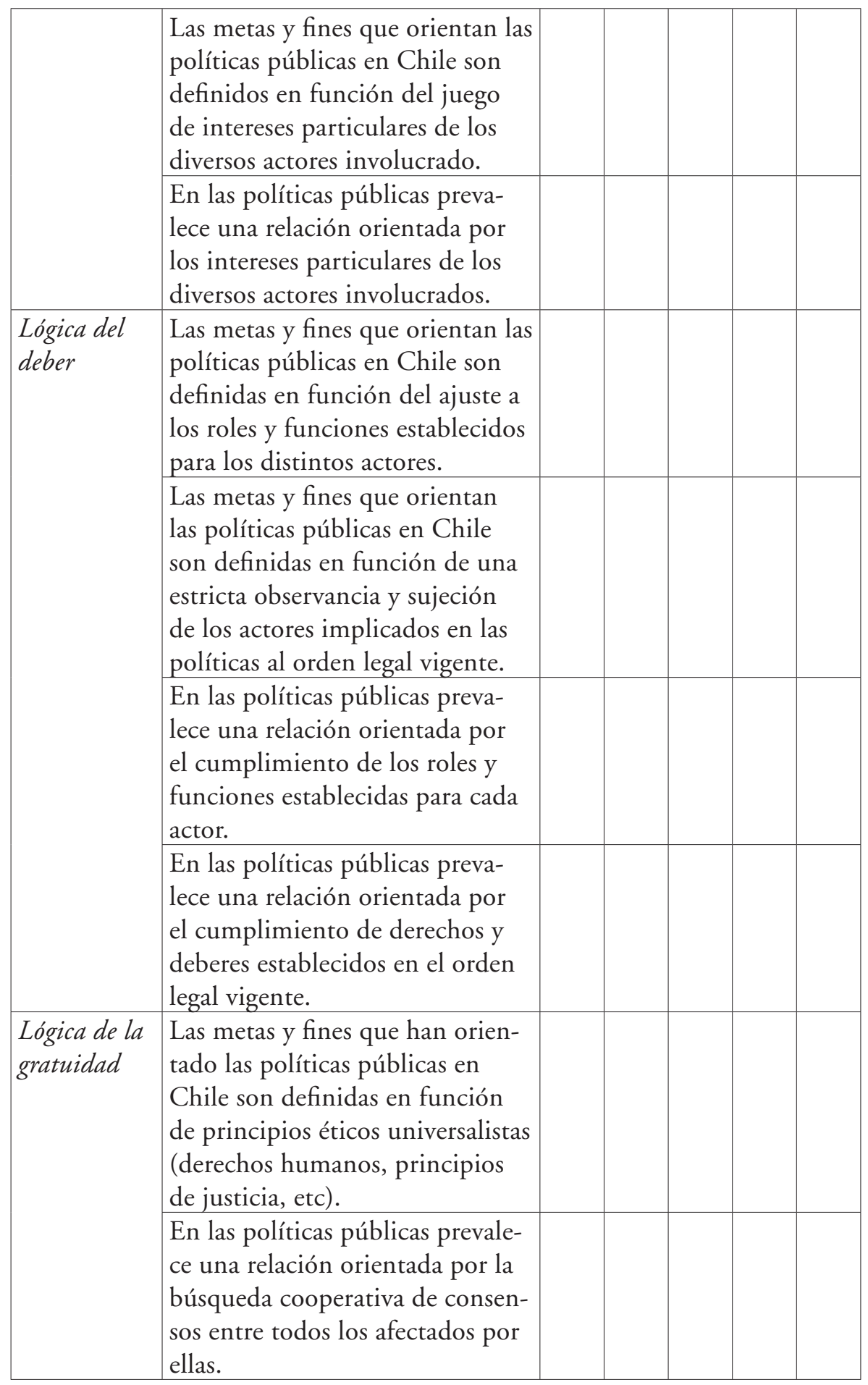




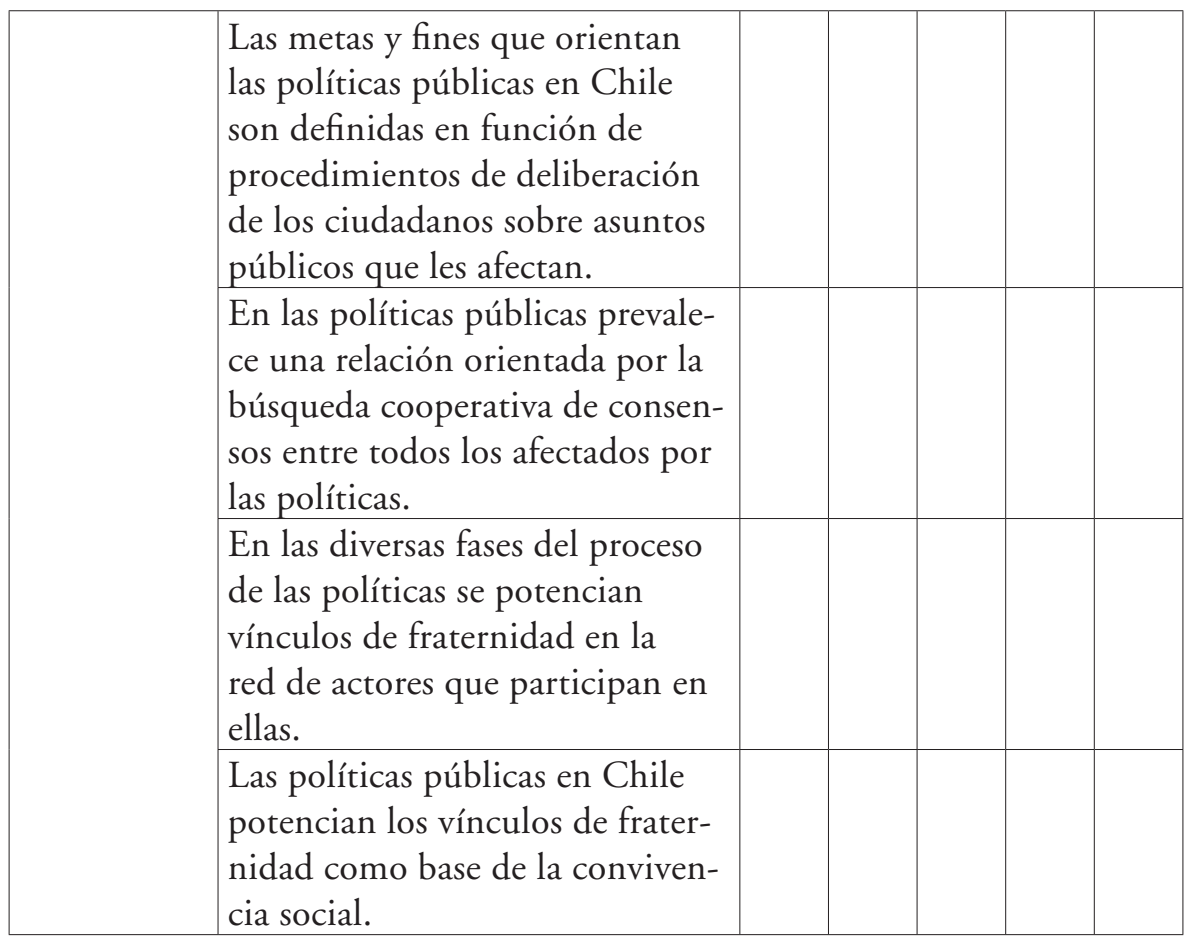

Como queda de manifiesto, el dispositivo propuesto consta de 14 reactivos, con 5 grados cada uno. De este modo, la escala teórica resultante tendría un valor mínimo $=14$ (muy en desacuerdo en todos los reactivos), y valor máximo=70 (muy de acuerdo en todos los reactivos). A efecto de simplificar la comprensión del índice, se opta al igual que el IDH de Naciones Unidas, llevarlo a una escala de 0 a 1 en donde, en este caso, 0 es total ausencia de Desarrollo Humano Integral, y 1 es total presencia de Desarrollo Humano Integral. Es así que el IDHI se calcularía como se indica para cada reactivo. El valor final sería el promedio de las puntuaciones de todos los reactivos.

$$
\begin{aligned}
& \text { Puntuación observada - puntuación mínima } \\
& \text { IDHI = } \\
& \text { Puntuación máxima - puntuación mínima }
\end{aligned}
$$

Además de calcular el IDHI en general, el paso siguiente consiste en analizar el comportamiento del índice en las distintas lógicas. De este 
modo, se obtendrían tres subíndices arrojando cada uno de ellos luces sobre la mayor o menor preponderancia de las distintas dimensiones. En cualquier caso, lo esperado para una política que presuponga una noción de desarrollo compatible con el DHI, debiera arrojar un alto valor del subíndice correspondiente a la lógica de la gratuidad. Las investigaciones hasta ahora realizadas a nivel de Fondecyt ${ }^{94}$, en donde se ha observado el nivel de normatividad preponderante (pre-convencional, convencional, post-convencional) en el caso de las políticas públicas en Chile, muestra que han prevalecido niveles pre-convencionales y convencionales, lo que puesto en relación con el IDHI, hablaría de la predominancia de las lógicas del tener y del deber. Ello podría ser explicado por la predominancia de un enfoque de desarrollo economicista y un concomitante modelo de análisis racional de las políticas públicas en el caso de Chile. De este modo, el IDHI aquí propuesto, se constituye en una primera versión de un dispositivo de observación del grado de expresión en política pública no solo de las predominantes lógicas del deber y del tener, sino también de la lógica de la gratuidad.

94 Proyectos Fondecyt Nº 1095186 y Nº1110428. 
Resumen: Se analiza la emergencia del concepto de desarrollo en sus coordenadas históricas y teóricas para poner en contexto su incorporación por Pablo VI. Ello articulado con una revisión crítica de los diversos modelos de desarrollo permite mejor comprender la tesis de Benedicto XVI que dice de la hegemonía de una concepción tecnológica del desarrollo en el presente. En la esfera de las políticas públicas se analiza en particular el modelo racional por su afinidad electiva con el enfoque economicista. Postulando que la fecundidad de la Doctrina Social de la Iglesia en la esfera pública, descansa tanto a nivel de la riqueza del concepto como de las posibilidades de su operacionalización, se propone un dispositivo de observación de las políticas que permita develar tanto la lógica dominante en ellas (del tener, del deber o de la gratuidad) como aportar a la formulación de políticas que articulen las tres esferas.

Palabras clave: Desarrollo, desarrollo humano integral, políticas públicas, doctrina social de la Iglesia, modelo racional.

Abstract: We analyze the emergence of the concept of development in his historical and theoretical context to put on incorporation by Paul VI. This articulated with a critical review of various development models can better understand the thesis of Benedict XVI says the hegemony of a technological concept of development in the present. In the area of public policy is discussed in particular the rational for their elective affinity with the economistic approach. Postulating that the fertility of the Social Doctrine of the Church in the public sphere, rests both the richness of the concept and the possibilities of their operation, we propose an observation device unveil policy allowing both dominant logic them (of having, of duty or gratuity) and contribute to the formulation of policies that link the three areas.

Keywords: Development, integral human development, public policy, social doctrine of the Church, rational model. 
